Viso - Cadernos de estética aplicada Revista eletrônica de estética

ISSN 1981-4062

No 23, jul-dez/2018

http://www.revistaviso.com.br/
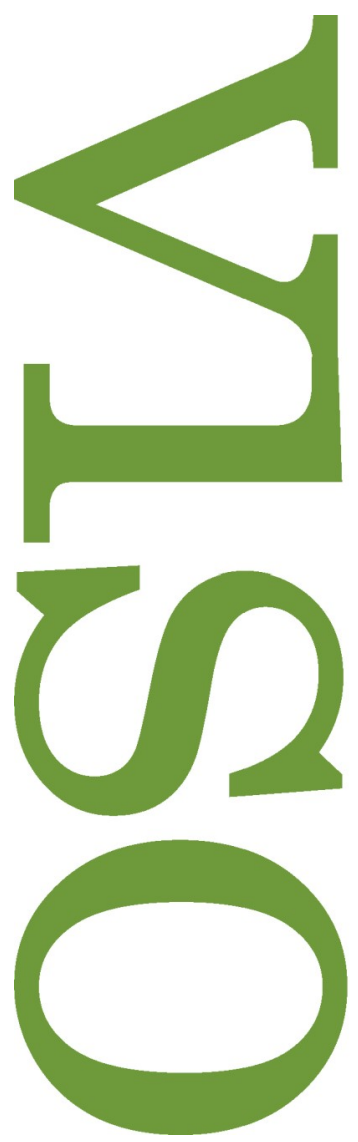

\title{
Sísifo infeliz No intenso agora Patrick Pessoa
}




\section{RESUMO}

\section{Sísifo infeliz No intenso agora}

No intenso agora é uma meditação sobre o suicídio baseada em uma perspectiva antipsicológica, de fortes tintas existencialistas. O mito de Sísifo, de Camus, é a obra filosófica com a qual o filme dialoga mais diretamente. Para defender esta tese, o filme de João Moreira Salles é inserido no contexto de um debate cinematográfico sobre as relações entre o suicídio e a política que inclui uma breve análise dos seguintes filmes: Trinta anos esta noite, de Louis Malle; O inquilino, de Roman Polanski; Os amantes constantes, de Phillipe Garrel; e Morrer aos trinta anos, de Romain Goupil, filme preferido de Salles sobre o período.

Palavras-chave: suicídio - Goupil - Camus - mito de Sísifo

\section{ABSTRACT}

\section{Unhappy Sisyphus In the Intense Now}

In the Intense Now is a meditation on suicide based on an anti-psychological perspective, of strong existentialist influence. Camu's The Myth of Sisyphus is the philosophical work with which the film dialogues more directly. In order to defend this thesis, the film by João Moreira Salles is inserted in the context of a cinematographic debate about the relations between suicide and politics that includes a brief analysis of the following films: Le feu follet, by Louis Malle; The Tenant, by Roman Polanski; Phillipe Garrel's Constant Lovers; and Mourir à trente ans by Romain Goupil, Salles' favorite film about the period.

Keywords: suicide - Goupil - Camus - myth of Sisyphus 
PESSOA, P. "Sísifo infeliz No intenso agora". In: Viso: Cadernos de estética aplicada, v. XII, n. 23 (juldez/2018), pp. 334-344.

\section{DOI: 10.22409/1981-4062/v23i/272}

Aprovado: 01.11.2018. Publicado: 27.12.2018.

(C) 2018 Patrick Pessoa. Esse documento é distribuído nos termos da licença Creative Commons Atribuição-NãoComercial 4.0 Internacional (CC-BY-NC), que permite, exceto para fins comerciais, copiar e redistribuir o material em qualquer formato ou meio, bem como remixá-lo, transformá-lo ou criar a partir dele, desde que seja dado o devido crédito e indicada a licença sob a qual ele foi originalmente publicado.

Licença: http://creativecommons.org/licenses/by-nc/4.0/deed.pt_BR

Accepted: 01.11.2018. Published: 27.12.2018.

(C) 2018 Patrick Pessoa. This document is distributed under the terms of a Creative Commons Attribution-NonCommercial 4.0 International license (CC-BY-NC) which allows, except for commercial purposes, to copy and redistribute the material in any medium or format and to remix, transform, and build upon the material, provided the original work is properly cited and states its license.

License: http://creativecommons.org/licenses/by-nc/4.0/ 
1.

Filmes de arquivo são uma grande inspiração para a prática da filosofia na Universidade. Ensaios compostos por uma montagem de imagens pré-existentes e de comentários em off feitos por quem selecionou as imagens e as organizou naquela ordem e com aquela duração. Se o gesto é retrospectivo, como o recuo daquele emblemático estudante francês que acaba de jogar uma pedra contra os policiais ${ }^{2}$, o objetivo é sempre em larga medida utópico: furar os escudos e capacetes da polícia, abrindo algumas cabeças.

No intenso agora é um filme de arquivo. Arranca fragmentos de imagens de lugares diversos - o filme caseiro feito pela mãe do cineasta na China, em outubro de 1966; imagens clássicas do maio de 1968 francês; filmagens-clandestinas do outono de Praga, também em 1968; o enterro do estudante Edson Luiz no Rio, no mesmo ano; trechos de filmes e obras literárias, entre outros - e os lança para algum lugar.

Duas perguntas vêm imediatamente à cabeça de seus espectadores:

(1) de onde vem o desejo do atirador de pedras?

(2) o que ele, intencionalmente ou não, acerta?

"Nem sempre a gente sabe o que está filmando", diz a voz do próprio João Moreira Salles, diretor e narrador de No intenso agora, nas sequências iniciais de seu filmeensaio. Ainda que, normalmente, essas palavras sirvam como uma boa diretriz para os críticos de arte, que devem duvidar sempre das intenções conscientes dos próprios autores de uma obra, no caso deste breve ensaio as minhas impressões sobre o filme vêm mescladas ao debate que Luiz Camillo Osorio, Imaculada Kangussu e eu realizamos com o próprio João Moreira Salles no cinema do Instituto Moreira Salles, no dia 22 de maio de 2018, logo após a projeção de No intenso agora para os participantes do IX Encontro do Grupo de Trabalho de Estética da ANPOF.

Alimentado talvez pela utopia de um mundo em que os acadêmicos escreveriam mais filmes do que teses ou artigos eruditos, e contaminado sem dúvida pela própria estrutura do filme que me proponho a comentar, este ensaio será composto por alguns flashes de imagens e de citações que me vieram à cabeça quando assisti ao filme pela primeira vez e quando o revejo agora pelas lentes da memória; por lembranças mais ou menos vívidas das palavras do próprio João durante o debate; e pelo intenso agora deste final de 2018, que tornou caducas algumas das palavras que eu havia escrito naquele distante maio, ainda às vésperas de todo o som e de todo a fúria que se seguiriam. 
A professora Katia Muricy disse numa aula, nos idos de 2008, que o filme sobre maio de 1968 de que ela mais tinha gostado havia sido Amantes constantes [Les amants réguliers], de Phillipe Garrel. Eu não conhecia o filme, mas, por conta desse comentário, resolvi vê-lo. Me lembro de ter ficado um pouco incomodado com o suicídio do protagonista no final. Achei derrotista usar a metáfora do suicídio como síntese retrospectiva daquele período. Tratava-se de um filme de ficção feito em 2005. E achei freudianamente bizarro que o diretor do filme tenha colocado o próprio filho, o ator Louis Garrel, no papel do suicida.

Eu jamais teria me recordado desse breve comentário da professora, que nada tinha a ver com a leitura do prefácio epistemo-crítico de $A$ origem do drama barroco alemão que então fazíamos, se não tivesse me deparado com uma frase parecida dita também um pouco à margem no filme No intenso agora. Em off, João Moreira Salles afirma que Morrer aos trinta anos [Mourir à trente ans], de Romain Goupil, é "o filme mais bonito sobre o período". E que, ao contrário do que eu supunha, o suicídio ficcional do protagonista no final do filme de Garrel era inspirado por uma série de suicídios reais de alguns dos protagonistas daquele intenso agora que foi o mês de maio de 1968 na França. Por mais que o filme seja multifacetado, e abra um número potencialmente infinito de possíveis relações entre 1968 e 2018, a questão do suicídio, notadamente em sua relação com a política, é um ponto de partida privilegiado para pensar ambos esses intensos agoras, assim como o entrecruzamento entre o ontem e o hoje.

\section{3.}

Chaves de ouro normalmente são utilizadas para fechar um livro, impulso natural mas de gosto duvidoso. Me pergunto, por exemplo, se Machado de Assis não seria tentado a rever o célebre desfecho das Memórias póstumas de Brás Cubas à luz dos incontáveis filhos (ou livros) que Brás gerou a partir de seu próprio: "Não tive filhos; não transmiti a nenhuma criatura o legado de nossa miséria". ${ }^{3}$

O jovem Camus, no entanto, entendeu que chaves de ouro também poderiam ser usadas para abrir uma reflexão. Começa seu ensaio em torno de O mito de Sísifo com uma das sentenças mais célebres da história da filosofia: "O suicídio é a única verdadeira questão filosófica. Saber se vale ou não vale a pena viver a vida é responder à questão fundamental da filosofia". ${ }^{4}$

No intenso agora pode ser lido como uma meditação sobre o suicídio: em primeiro lugar, sobre o suicídio da mãe do cineasta, que é o fio condutor não declarado de todo o filme. Uma confissão do narrador - "Na minha memória, nada deixava minha mãe tão acesa quanto a lembrança daquele tempo. Era com gosto que ela falava, com alegria, com uma 
intensidade que o tempo viria a the roubar. Ela foi feliz na China, e por isso gosto de pensar nela lá, quando tudo parecia possível" - serve de mote à questão que estrutura o discurso do filme como um todo: como é possível sobreviver a um intenso agora? O que fazer quando a vida retorna à sua planejada normalidade? Quando tudo, num repente, perde a beleza do que se dá de modo imprevisível?

4.

O inquilino, de Roman Polanski, é uma das mais fecundas reflexões cinematográficas sobre o suicídio. Trata-se de investigar até que ponto é possível entrar na pele de alguém que se mata, até que ponto é possível identificar-se afetivamente com um suicida a ponto de "entender os seus motivos". Evidentemente, o duplo suicídio do protagonista (não por acaso vivido pelo próprio diretor) revela uma posição contundente: só entende um suicida quem também se mata. A identificação empática só se consuma com a imitação do gesto derradeiro. E, ainda assim, só se pode morrer a própria morte. A sobriedade antipsicológica converte-se em imperativo ético.

Sob essa ótica, torna-se talvez compreensível o silêncio do narrador em torno do suicídio da mãe. $E$ também a tentativa de, em alguma medida, dar-lhe um enquadramento mais amplo - ou épico - do que o da mera dor individual - não raro reduzida à esfera do drama psicológico ou das psicopatologias burguesas.

5.

Luiz Camillo Osorio, no ensaio sobre o filme que integra esta edição da Viso, formula uma questão a meu ver decisiva: "Não teria a história da mãe contaminado em demasia a leitura de João Moreira Salles dos desdobramentos de maio de 68?"

6.

O próprio João Moreira Salles, no dia do debate no IMS, de certa forma respondeu à provocação de Camillo: "Aprendi com Eduardo Coutinho que as duas palavras mais pornográficas da língua portuguesa (de qualquer língua!) são 'pureza' e 'perfeição'. Me interessava problematizar a idealização de maio de 1968 feita por diversos atores políticos dos dias atuais".

O filme, segundo relatou o cineasta, começou a ser gestado no longínquo ano de 2011, com Lula ainda presidente e os movimentos sociais brasileiros vivendo talvez o seu momento de maior aceitação institucional. E tornou-se ainda mais urgente com as 
grandes manifestações ocorridas em 2013 mundo afora, cujo parentesco com as grandes manifestações de maio de 1968 é inequívoco.

Em 2018, quando realizamos o debate, o Brasil era outro. Perguntei até que ponto o projeto inicial se sustentava dada a radical mudança de contexto histórico no país e no mundo. Em 2018, com Trump na presidência dos EUA e Bolsonaro às portas do Planalto, de que lado do espectro político nacional estaria a apologia da pureza e da perfeição? Ainda mais em se tratando de um partido como o PT e de um estadista como Lula, recriminado justamente pelos "acordos espúrios" realizados com setores reacionários do PMDB, os mesmos setores que articularam o golpe de 2016, será mesmo que um apreço desmedido por "pureza e perfeição" seriam valores facilmente atribuíveis à esquerda brasileira?

Basta ir a uma manifestação dos camisas verde e amarela da CBF, dos vociferadores do "ame-o ou deixe-o" e do "Vai pra Cuba", para saber quem são, hoje, os verdadeiros arautos da pureza e da perfeição.

Em outras palavras: transformações históricas como as que vivemos entre a origem do projeto de No intenso agora e o momento em que escrevo este texto são capazes de alterar de modo profundo o "sinal ideológico" de uma obra. A "mesma" obra, em contextos distintos, significa coisas inteiramente diferentes.

A melancolia exalada por No intenso agora seria bem mais digerível se vivêssemos em um momento menos sombrio. Ser melancólico, e o já citado Brás Cubas não me deixa mentir, sempre foi uma prerrogativa dos poderosos.

7.

Mas será possível afirmar de forma unívoca que No intenso agora é um filme melancólico ou mesmo pessimista, como disseram alguns críticos, dentre os quais Imaculada Kangussu no outro texto comentando o filme que integra esta edição da Viso?

8.

Morrer aos trinta anos, o filme preferido de João Moreira Salles sobre o período, começa com uma série de cartelas negras com os nomes de pessoas aos quais o filme é dedicado. Embora o título do filme evoque a célebre meditação de Louis Malle, de tintas existencialistas, sobre o tema do suicídio, a analogia não é senão aparente.

O filme de Malle - cujo título original, Le feu follet, ou "O fogo fátuo", encontrou na "criatividade" de seu tradutor para o português uma inflexão inesperada e passou a se 
chamar Trinta anos esta noite - é a odisseia de um dia na vida de um homem que, por volta dos trinta anos, convalescendo em uma clínica de reabilitação para alcoólatras, decide se suicidar. Ele resolve então, em seu último dia de vida, ir visitar os seus antigos amigos de juventude, quando a vida era um só intenso agora feito de sexo, drogas, rock'n roll e passatempos de gosto duvidoso.

Amadurecer, para o protagonista vivido por Maurice Ronet, tornou-se insuportável. A nostalgia dos anos de ouro, um fardo que só era possível carregar enquanto ele se embriagava diariamente. Sem o álcool, instalam-se o tédio e a angústia. A apatia. No reencontro com os velhos amigos, ele tem uma pergunta apenas: que outros sentidos para a existência vocês encontraram para seguir vivendo? Que razões têm para se levantar da cama todas as manhãs?

São múltiplas as respostas que seus antigos amigos Ihe fornecem: casamento, filhos, o estudo apaixonado do antigo Egito, a vida de professor, continuadas experiências com as drogas e a poesia, ações políticas mais ou menos arriscadas (ainda que sem uma direção clara), o dinheiro que compra jantares faustosos, conversas esporádicas com os intelectuais da moda.

Sob a ótica desse homem votado ao suicídio, porém, todas essas respostas parecem a confissão de uma derrota, a aceitação de uma existência medíocre, sem aquela intensidade que para ele seria a única justificação possível para uma vida digna de ser vivida. Finda a investigação, o protagonista retorna à clínica e se mata com um tiro no peito. O filme termina com a sua carta de suicida, na qual explica a sua incapacidade de viver, de "realmente tocar e ser tocado pelas coisas", e confessa a vontade de fazer com que o seu suicídio seja uma "marca indelével" nas vidas daqueles que optaram por seguir vivendo.

\section{9.}

Um suicídio é sempre uma marca indelével em quem fica, especialmente nas vidas das pessoas mais próximas. Por mais que se encontrem explicações mais ou menos apaziguadoras para esse gesto extremo - depressão, drogas, inadequação à vida em sociedade, um trauma psicológico qualquer -, um suicídio nos lega sempre uma questão até certo ponto irrespondível, aquela mesma que, segundo Heidegger, estaria na base das investigações dos metafísicos de todos os tempos: "Por que o ser e não antes o nada?"

Em Morrer aos trinta anos, Goupil mostra imagens de seu arquivo pessoal e conta a história de sua amizade com Michel Recanati. Tendo se conhecido em 1965, o primeiro se torna um militante de extrema-esquerda e um dos líderes da Juventude Comunista. Já Goupil se torna um dos porta-vozes do Comitê de Ações dos Liceus. Ambos vivem juntos 
a fervura dos anos pré- e pós-maio de 1968, fazendo da política o centro e o sentido de suas vidas. Juntos, realizam uma série de ações estético-políticas que se poderiam rotular como "artivistas", embora no caso deles a arte seja muito menos decisiva do que o ativismo.

A sorte de Goupil é que seu pai e ele próprio registraram muitas dessas ações em película. Assim, revendo os seus arquivos muitos anos depois, ele constrói uma reflexão sobre os seus anos de juventude. Uma reflexão que, como as telas iniciais com os nomes dos amigos suicidados deixam didaticamente claro, tem como objetivo não apenas entender o que foi e o que é, o que efetivamente estava em jogo nas vidas daqueles jovens militantes e o que está ainda em jogo nas vidas dos sobreviventes, mas sobretudo elaborar o luto pelo suicídio de Recanati, que se matou em 1978.

"O absurdo [a falta de sentido para a existência], tomado até aqui como conclusão, será considerado neste ensaio como ponto de partida". Essas palavras, escritas pelo jovem Albert Camus no prólogo ao leitor de O mito de Sísifo, poderiam também abrir o filme de Goupil. Afinal, por mais que ele se inicie com os nomes dos que se mataram, o que se vê na sequência são ações políticas e a história de uma amizade com rasgos de uma humanidade tão intensa, ou de uma intensidade tão humana, que de forma alguma o filme termina em chave melancólica. Sim, Recanati viveu anos absolutamente intensos em sua juventude de militante. Mas será que ele se matou quando se viu forçado a crescer, a abandonar as suas "ilusões políticas" de juventude? Quando se viu forçado "a lidar com uma nostalgia assim tão precoce"?

A resposta do diretor-ensaísta Romain Goupil faz uso de uma torção psicológica que, a meu ver, neste caso se justifica. Ainda que todo o decurso do filme possa dar a impressão de que seria impossível seguir vivendo com um mínimo de dignidade após o que, sob certa ótica, poderia ser lido como a derrota dos movimentos esquerdistas de 1968 - uma derrota que Morrer aos trinta anos enfatiza muito menos e sem dúvida de forma muito mais matizada do que No intenso agora -, Goupil vale-se, no quarto final do filme, de uma série de referências à vida familiar de Recanati, sobretudo à difícil relação que tinha com seu pai, para assim tornar mais ambíguo o seu suicídio. Contrariando a tendência de usar a psicologia para dar explicações simplistas às tragédias da vida, Goupil a usa em seu filme para desfazer a simplória relação de causalidade entre a desilusão com a política e o suicídio.

Assim, ao final de Morrer aos trinta anos, não sabemos por que Recanati se matou. Por mais que possamos suspeitar que a derrota política tenha sido um fator a sobredeterminar o seu suicídio, o fato de que as ações realizadas pelos dois amigos sejam vividas e filmadas de modo tão alegre e mesmo tão leve - ainda que o assunto e as ações de ambos sejam graves - nos deixam com um travo feliz na boca. 
A montagem de Morrer aos trinta anos, em suma, mostra que começar por esse sentimento do absurdo que às vezes engendra suicídios não necessariamente gera uma obra melancólica. Muito pelo contrário.

10.

No contraste com o filme de Goupil, as opções feitas pelos montadores de No intenso agora tornam-se mais visíveis. Uma coisa é começar com o suicídio e terminar com a alegria - nem que seja a alegria de fazer um filme, ou de fazer política, duas ações que tendem a se confundir (ainda que de modos mais ou menos explícitos). Outra coisa é começar com a alegria de um intenso agora, seja ele na China de Mao ou nas ruas de Paris, e terminar com uma série de suicídios, como se fosse esse o destino inelutável de toda uma geração que efetivamente acreditou na política.

11.

Golpe, estado de exceção, ditadura do judiciário. Dilma deposta, um usurpador no poder, Lula preso. Após treze anos de inegáveis progressos sociais, a vitória da reação: perda dos direitos dos trabalhadores, venda do pré-sal, um neofacista a dois passos do Palácio do Planalto. Mas será que o triunfo da reação é mesmo sempre inevitável?

Os exemplos apresentados no filme No intenso agora parecem apontar nessa direção: De Gaulle dá a palavra final e cala o movimento estudantil - o plano da discussão entre o sindicalista e o estudante quase fora de quadro no final do filme são interpretados pelo narrador neste sentido; "Sob os paralelepípedos, a praia" não passaria de uma frase de efeito de um gênio da propaganda; os tanques russos dão a palavra final e encerram a Primavera de Praga; no Brasil, a indignação em torno da morte do estudante Edson Luiz pôde pouco ou nada diante da resposta ainda mais violenta dos milicos.

"Estranho outono mostra como a vida se acomoda. Mesmo as pessoas decentes não demorarão muito para se acomodar à nova ordem." Essa definição de Estranho outono valeria também para No intenso agora?

Por que, a despeito da "derrota" dos manifestantes sob uma perspectiva macropolítica, o filme investiga tão pouco as suas vitórias, aquilo que sobreviveu micropoliticamente no corpo e nas atitudes críticas e contestadoras das gerações seguintes? Mesmo sob um viés macropolítico, não houve conquistas duradouras em 1968 para os sindicatos e mesmo para os estudantes? São perguntas apenas, que o filme não se faz. 
12.

Após ver O processo, de Maria Augusta Ramos, rever No intenso agora me deixou com a impressão de que há muitas coisas piores que a morte. Ver os senadores unidos em torno da defesa da legitimidade do mandato de Dilma, mesmo com a certeza da derrota, num clima de "encantamento com a política", de estar do lado certo da história, me fez pensar no seguinte: no final, importam pouco as vitórias e as derrotas. O que importa é falar com o corpo dentro, preservando o humor e a doçura. $O$ engajamento existencial está acima de seus possíveis resultados. Mesmo quando a derrota é certa, a vitória é estar lá, no embate dos corpos, na disputa pelos discursos que prevalecerão. Talvez não no presente mais imediato, mas na história. Viver o presente sob a perspectiva da utopia. Não é esse, no final das contas, o melhor antídoto para o suicídio?

Não é esse, enfim, o sentido da chave de ouro com que Camus encerra o seu mito decisivo, O mito de Sísifo? "A própria luta em direção aos cimos é suficiente para preencher um coração humano. É preciso imaginar Sísifo feliz". ${ }^{5}$

\footnotetext{
* Patrick Pessoa é professor do Departamento de Filosofia da UFF.

1 BANDEIRA, M. "O último poema". In: Estrela da vida inteira. Rio de Janeiro: José Olymio, 1989, p. 119.

${ }^{2}$ No minuto 27 do filme No intenso agora, João Moreira Salles descreve a imagem de um homem atirando uma pedra contra a polícia com as seguintes palavras: "Maio em Paris. Do acervo de gestos de 68 , este é o mais marcante. O corpo envergado para trás, o braço em estilingue, a energia represada a um segundo da descarga. O giro de atleta olímpico. E, quase sempre, o recuo".
}

${ }^{3}$ MACHADO DE ASSIS, J. M. Memórias póstumas de Brás Cubas, capítulo CLX.

${ }^{4}$ CAMUS, A. Le mythe de Sisyphe. Paris: Gallimard, 1969, p. 15.

${ }^{5}$ Ibidem, p. 166. 